\title{
UJI COBA LAMPU CELUP LED PADA JARING INSANG SEBAGAI UPAYA MENINGKATKAN HASIL TANGKAPAN
}

\section{TRIALS OF LED UNDERWATER LAMP ON THE GILLNET AS AN EFFORT TO INCREASE THE CATCH}

\author{
Angga Hartono ${ }^{1}$, Gondo Puspito², Wazir Mawardi ${ }^{2}$ \\ ${ }^{1}$ Program Studi Teknologi Perikanan Laut, Sekolah Pascasarjana \\ ${ }^{2}$ Departemen Pemanfaatan Sumberdaya Perikanan \\ Fakultas Perikanan dan Ilmu Kelautan, Institut Pertanian Bogor \\ Korespondensi: angga.hartono@yahoo.co.id,gondopuspito@gmail.com,wmawardi@gmail.com
}

\begin{abstract}
Gillnets is a rectangular fishing gear. The main principle of the methods is blocking movement of the fish. The success of its operation depends on the fish presence in passing the net. The improvements of fishing technique on gillnets need to be done to increase the catch weight. The solution is to innovate the use of attractors in the form of lights to attract fish to come to the fishing gear, so that the passive gillnets do not just wait for the fish through it. The study used experimental fishing method with two units of gillnets simultaneously, which each units with lamp and the other without lamp. The objectives of the studies are to get information on the catch composition, to prove the use of a lamp on the gillnets will increase the catch weight and to determine the net position from the lamp that resulted the highest weight. The result showed that (1) the catch in gillnets with LED underwater lamps (JDL) consist of 10 types, or 2 types more than the gillnets without light emitting diode (LED) lamp (JTL). The eight catch composition consists of mackerel, spanish mackerel, barred queenfish, indian mackerel, great barracuda, moonfish, bigbelly pomfret, and giant trevally. The catch composition from JDL were the amberjack and the black pomfret; (2) The use of lamp on the gillnet proven to increase the catch with JDL total weight of fish was $189.765 \mathrm{~g}$; (3) from position of the net shows that the highest weight was at the first position, such as net number 1, 6, 7, and 12 as much as $108.308 \mathrm{~g}$.
\end{abstract}

Keyword: Binuangeun, chip on board, gillnet, light fishing

\begin{abstract}
ABSTRAK
Jaring insang merupakan alat penangkap ikan berupa lembaran jaring yang berbentuk persegi panjang. Prinsip utama pengoperasiannya adalah menghadang pergerakan ikan. Keberhasilan operasi penangkapannya sangat tergantung pada ada atau tidaknya ikan yang melintas melewati jaring. Perbaikan teknik penangkapan ikan pada jaring insang perlu dilakukan untuk meningkatkan berat tangkapannya. Solusinya adalah inovasi penggunaan atraktor berupa lampu untuk menarik perhatian ikan agar datang menuju alat tangkap, sehingga jaring insang yang bersifat pasif tidak hanya menunggu ruaya ikan yang melewatinya. Salah satu sumber cahaya yang bisa digunakan adalah lampu LED. Metode penelitian yang digunakan adalah experimental fishing menggunakan dua unit alat tangkap jaring insang yang dioperasikan secara bersamaan, masing-masing menggunakan lampu dan tanpa lampu. Tujuan yang ingin dicapai adalah mengetahui komposisi hasil tangkapan, membuktikan bahwa penggunaan alat bantu lampu pada jaring insang akan meningkatkan berat hasil tangkapan dan menentukan posisi jaring dari lampu yang menghasilkan berat tangkapan tertinggi. Hasilnya adalah: (1) Ikan hasil tangkapan jaring insang dengan lampu (JDL) terdiri atas 10 jenis, atau 2 jenis lebih banyak dibandingkan dengan jaring insang tanpa lampu (JTL). Delapan jenis ikan yang sama adalah tongkol, tenggiri, talangtalang, alu-alu, kembung, semar, galang sadap, dan kwee. Adapun 2 jenis ikan yang hanya tertangkap oleh JDL adalah tentengkek dan bawal hitam; (2) Penggunaan alat bantu lampu pada jaring insang terbukti meningkatkan hasil tangkapan dengan berat hasil tangkapan JDL $189.765 \mathrm{~g}$, dan (3) Lembar jaring yang menghasilkan berat tangkapan tertinggi berada pada posisi pertama, yaitu lembar 1, 6, 7, dan 12 dengan hasil tangkapan sebesar $108.308 \mathrm{~g}$.
\end{abstract}

Kata kunci: Binuangeun, chip on board, gillnet, light fishing 


\section{PENDAHULUAN}

Jaring insang merupakan alat penangkap ikan berupa lembaran jaring yang berbentuk persegi panjang. Jumlah mata ke arah horizontal lebih banyak dibandingkan dengan ke arah vertikal. Bagian atas jaring diberi tali ris atas untuk menggantungkan jaring dan tali pelampung yang dilengkapi dengan deretan pelampung (floats). Jaring juga dilengkapi dengan tali ris bawah dan tali pemberat yang dilengkapi dengan beberapa pemberat (sinkers) (Puspito 2009). Adanya gaya apung (buoyancy force) pelampung dan gaya tenggelam (sinking force) pemberat menyebabkan jaring akan terentang membentuk bidang persegi ketika dioperasikan (Baskoro dan Yusfiandayani 2015).

Prinsip utama pengoperasian jaring insang adalah menghadang pergerakan ikan di suatu perairan, baik pada siang maupun malam hari (Fitri dan Asriyanto 2011). Keberhasilan operasi penangkapannya sangat tergantung pada ada atau tidaknya ikan yang melintas melewati jaring (Surahman dan Kuswoyo 2016). Prinsip pengoperasian jaring insang yang sama juga diterapkan oleh nelayan Binuangeun, Kabupaten Lebak, Banten.

Hasil tangkapan jaring insang nelayan Binuangeun belum optimal atau tingginya tingkat ketidakpastian dalam mendapatkan hasil tangkapan menyebabkan nelayan terkadang tidak mendapat hasil tangkapan sama sekali. Penyebab utamanya adalah adanya persaingan antara sesama pengguna jaring insang maupun jenis alat tangkap lainnya yang dioperasikan pada daerah penangkapan yang sama untuk tujuan penangkapan jenis-jenis ikan pelagis (Wiyono 2012; Direktorat kredit, BPR dan UMKM 2008). Selain itu, jumlah hasil tangkapannya juga sangat dipengaruhi oleh musim (Salas et al. 2004).

Beberapa nelayan melakukan berbagai upaya untuk meningkatkan hasil tangkapan, diantaranya berupa penambahan panjang jaring, diversifikasi alat, pengoperasian lebih dari satu alat pada waktu bersamaan dan menambah lama trip penangkapan (Wiyono 2012). Sementara penyelesaian terhadap hasil tangkapan nelayan lainnya agar menjadi lebih baik perlu dilakukan. Solusinya adalah inovasi penggunaan atraktor berupa lampu untuk menarik perhatian ikan agar datang menuju alat tangkap, sehingga jaring insang yang bersifat pasif tidak hanya menunggu ruaya ikan yang melewatinya (Iskandar et al. 2007).

Penggunaan lampu memanfaatkan indera penglihatan ikan (Gunarso 1985; Cahyadi dan You 2016). Syam dan Satria (2009) menambahkan bahwa mata ikan dapat merespon cahaya, baik cahaya terang maupun redup. Ikan juga memiliki sifat ketertarikan untuk mendekati sumber cahaya (Notanubun dan Patty 2010; Sudirman dan Nessa 2011). Beberapa penelitian menggunakan cahaya sebagai alat bantu dengan memanfaatkan penglihatan ikan, seperti pada perikanan jaring insang lingkar dengan atraktornya berupa drift rumpon lampu (Imron et al. 1997), rumpon lampu (Imron dan Iskandar 1998), dan penggunaan lampu pada jaring insang (Sokimi dan Beverly 2010).

Jenis lampu yang digunakan untuk penangkapan ikan dengan jaring insang adalah LED yang dicelup ke dalam air. Beberapa keunggulannya, menurut Setiawan et al. (2015), meliputi intensitas cahayanya tinggi, sumber energinya hanya berupa baterai kering dan usia pakainya sangat panjang yaitu mencapai 30.000 jam, ukurannya kecil sehingga praktis untuk dioperasikan (Suhardi 2014) serta harga lampu dan biaya operasionalnya relatif rendah (Arif et al. 2015). Penelitian ini bertujuan untuk menentukan komposisi jenis hasil tangkapan jaring insang, baik yang tanpa atau dengan alat bantu lampu; membuktikan bahwa penggunaan alat bantu lampu pada jaring insang akan meningkatkan berat hasil tangkapan; dan menentukan posisi jaring dari lampu yang menghasilkan tangkapan dengan berat tertinggi.

\section{METODE PENELITIAN}

Penelitian menggunakan metode percobaan (experimental fishing) yang dikelompokkan ke dalam dua tahap. Masing-masing adalah pembuatan 6 unit lampu celup LED di Laboratorium Teknologi Alat Penangkapan Ikan, Departemen Pemanfaatan Sumberdaya Perikanan, Fakultas Perikanan dan Ilmu Kelautan, Institut Pertanian Bogor, antara SeptemberOktober 2018. Berikutnya, uji coba lampu pada operasi penangkapan ikan dengan jaring insang yang dilakukan antara Februari-Maret 2019. Lokasinya berada di Perairan Binuangeun, Kabupaten Lebak, Provinsi Banten (Gambar 1). 


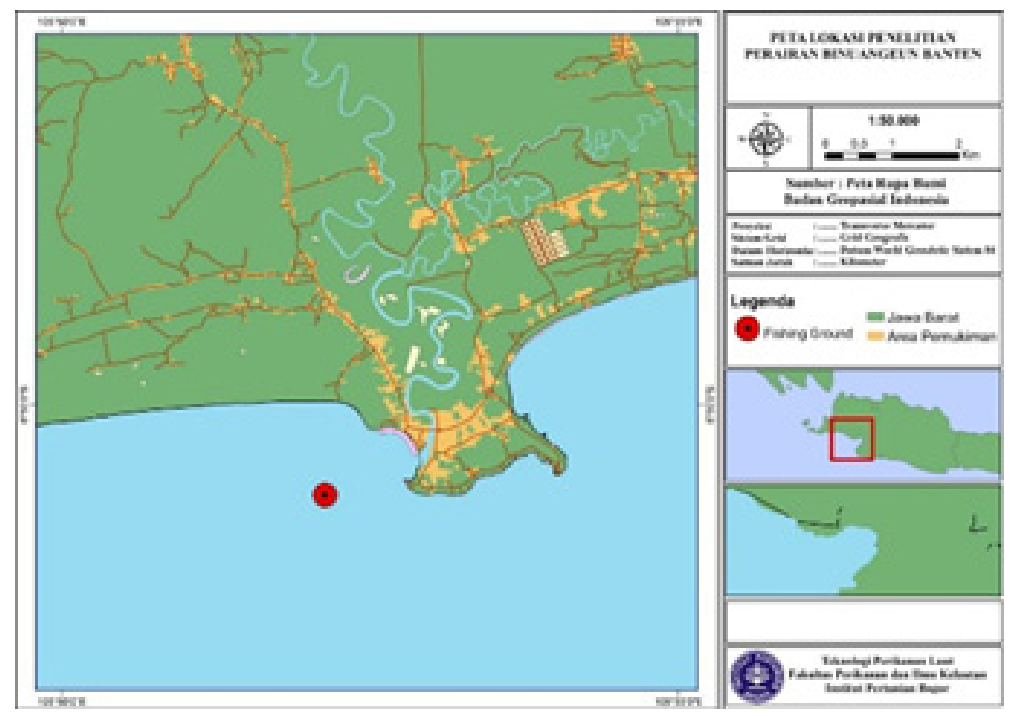

Gambar 1. Peta lokasi penelitian

\section{Pembuatan lampu celup LED}

Satu unit lampu celup LED tersusun atas dua keping LED COB (chip on board) dengan spesifikasi $12 \mathrm{~V}, 75 \mathrm{Watt}$. Intensitas cahaya tertinggi sebesar 148 lux dengan pancaran cahaya berwarna putih. Menurut Susanto et al. (2017), ikan lebih cepat merespon cahaya berwarna putih dibandingkan dengan warna lainnya. Sumber energinya berasal dari 3 unit baterai kering $4 V$ 1,6 $A H$ merek Krisbow yang disusun secara seri. Silikon digunakan pada bagian tutup setoples untuk menghindari perembesan air laut. Selanjutnya, seluruh komponen dimasukkan ke dalam setoples plastik transparan berukuran $11 \times 7 \mathrm{~cm}$ $(\mathrm{t} \times \Phi)$. Gambar 2 menjelaskan komponenkomponen dan satu unit lampu celup yang dilengkapi dengan 2 pemberat timah@300 g.

Pemilihan jenis lampu LED COB juga dipertimbangkan karena dioperasikan di dalam air dan adanya kemungkinan terkena rembesan air laut akibat kesalahan dalam pemasangan atau kejadian yang tidak terduga. Lampu LED COB dipilih karena tahan terhadap air dan harga relatif murah. Adapun pemilihan spesifikasi lampu COB tersebut berdasarkan pertimbangan dari segi dimensi, intensitas, harga, serta hasil uji coba ketahanan beberapa LED dengan daya berbeda, maka LED yang digunakan pada saat penelitian dipilih karena mampu bertahan selama \pm 12 jam, mudah dirangkai dan praktis ketika dioperasikan.

\section{Uji coba penangkapan}

Jumlah jaring insang yang dioperasikan sebanyak 2 unit, masingmasing terdiri atas 12 lembar jaring. Satu unit jaring insang tidak dilengkapi dengan lampu celup LED, sedangkan lainnya dilengkapi dengan 3 lampu celup LED dengan jarak pemasangan sekitar $240 \mathrm{~m}$. Gambar 3 menunjukkan spesifikasi dan posisi penempatan 3 unit lampu LED pada lembar jaring pertama, diantara lembar ke-6-7 dan lembar 12. Selanjutnya, setiap unit jaring insang dioperasikan oleh perahu berbeda yang berjarak sekitar $100 \mathrm{~m}$ antara Satu perahu dengan perahu lainnya ketika dioperasikan. Berdasarkan pengukuran intensitas cahaya di udara didapatkan pancaran terjauh berjarak $13 \mathrm{~m}$ dari sumber cahaya. Sehingga pada jarak $100 \mathrm{~m}$ tidak akan mempengaruhi JTL.

Pengoperasian jaring insang mengikuti operasi penangkapan yang biasa dilakukan oleh nelayan mulai pukul 17.30 hingga pukul 02.00 WIB. Urutannya dimulai dari keberangkatan menuju daerah penangkapan ikan, persiapan jaring insang, pemasangan lampu pada jaring dan penurunan atau setting jaring dilakukan 1 kali. Hauling atau pengangkatan jaring sembari penyortiran dilakukan setelah soaking time selama \pm 8 jam. Pengambilan data dilakukan ketika dilakukan penyortiran ikan dengan menimbang seluruh berat ikan. Jenis datanya meliputi jenis, berat ikan (gram) dan posisi ikan tertangkap (lembar jaring ke-). 

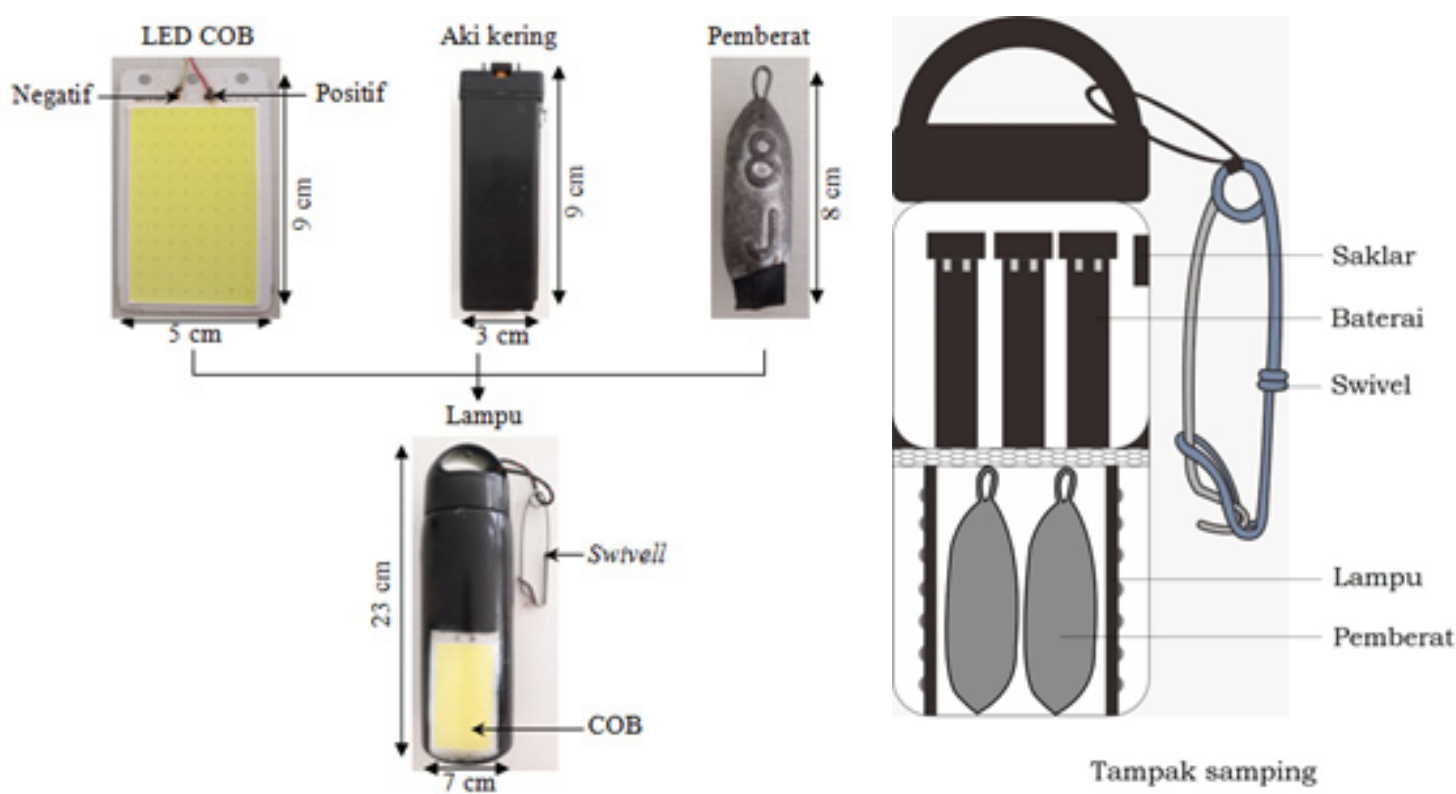

Tampak samping

Gambar 2. Konstruksi lampu celup LED dan komponennya

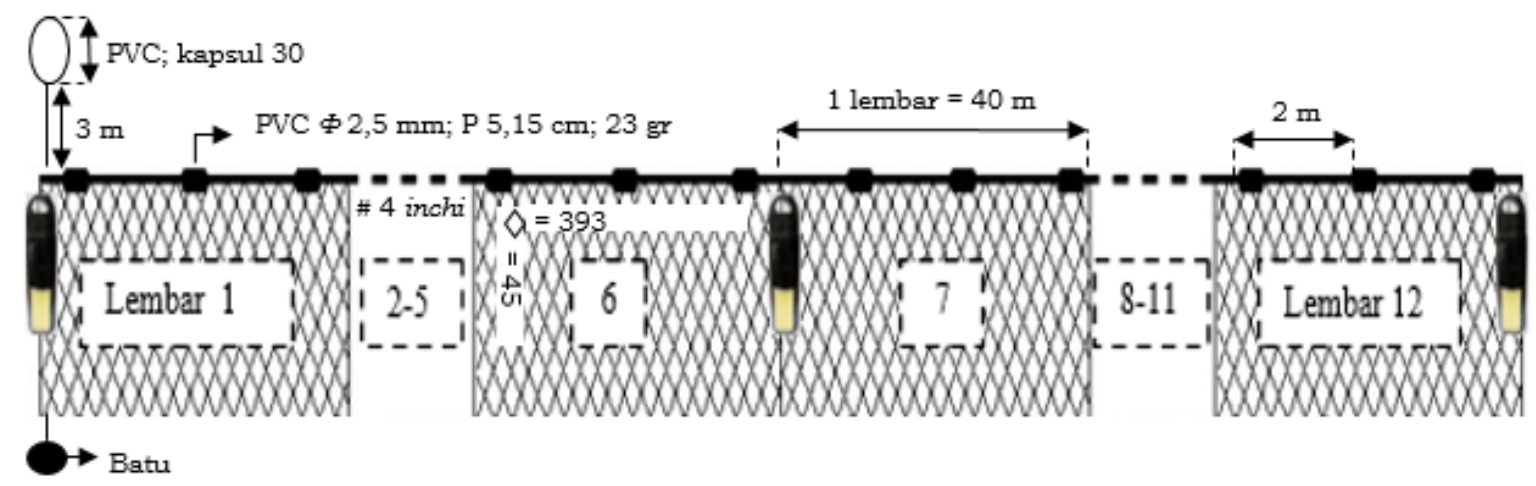

Gambar 3. Spesifikasi jaring dan posisi penempatan lampu pada jaring insang

\section{Analisa data}

Data berupa jenis, bobot dan posisi hasil tangkapan dianalisis secara deskriptif dan uji statistik. Analisis deskriptif dilakukan dengan membuat diagram untuk melihat perbandingan hasil tangkapan masing-masing jaring insang. Adapun uji satistik digunakan untuk menguji hipotesis. Tahapan analisisnya dimulai dengan uji normalitas data menggunakan metode Kolmogorov Smirnov. Kemudian di lanjutkan dengan uji non parametrik. Pengujian hipotesisnya menggunakan statistik uji Mann Whitney dengan formula:

1. $U_{1}=n_{1} \cdot n_{2}+\frac{n_{2}\left(n_{2}+1\right)}{2}-R_{2} ; \mathrm{dan}$

2. $U_{2}=n_{1} \cdot n_{2}+\frac{n_{1}\left(n_{1}+1\right)}{2}-R_{1}$

Nilai kristis yang digunakan adalah $0,05 . \quad H_{0}$ ditolak apabila berada dalam wilayah kritis (Walpole et al. 2007). Sementara uji Kruskal Wallis digunakan untuk mengolah data berat hasil tangkapan berdasarkan jarak lembar jaring dari lampu. Formulanya adalah:

$$
H=\frac{12}{n(n+1)}=\sum_{i=1}^{k} \frac{r_{i}}{n_{i}}-3(n+1)
$$

$H$ adalah nilai statistik uji, $N i$ jumlah data kelompok $i$, ri nilai peringkat kelompok $i$, dan $K$ jumlah kelompok data. $H_{o}$ ditolak apabila nilai signifikansinya kurang dari 0,05.

\section{HASIL DAN PEMBAHASAN}

\section{Komposisi hasil tangkapan jaring insang}

Ikan yang didapatkan dari hasil pengoperasian jaring insang (Gambar 4) terbagi atas dua kelompok, yaitu jenis ikan hasil tangkapan utama (HTU) dan sampingan 
(HTS). Jenis ikan HTU merupakan ikanikan pelagis yang merupakan tujuan penangkapan. Adapun ikan HTS adalah jenis ikan-ikan yang bukan menjadi tujuan utama penangkapan dengan jaring insang namun dapat dimanfaatkan.

Kelompok ikan HTU yang tertangkap oleh jaring insang terdiri atas 3 jenis ikan pelagis besar. Beratnya mencapai 232.874 g. Rinciannya adalah tongkol (Euthynnus affinis) seberat $132.387 \mathrm{~g}$, tenggiri (Scomberomorus commerson) (98.112 g), dan talang-talang (Scomberoides tala) $(2.375 \mathrm{~g})$. Ikan HTS yang tertangkap sebanyak 7 jenis. Total beratnya mencapai $59.466 \mathrm{~g}$. Masingmasing adalah kembung (Rastrelliger kanagurta) (21.524 g), alu-alu (Sphyraena barracuda) (3.655 g), galang sadap (Brama orcini) $(14.200 \mathrm{~g})$, semar (Mene maculata) (11.319 g), kwee (Caranax ignobilis) (6.988 g), tentengkek (Seriolina nigrofasciata) (1.280 g), dan bawal hitam (Parastromateus niger) (500 g). Gambar 5 menjelaskan komposisi berat hasil tangkapan jaring insang.

Hasil tangkapan sampingan (HTS) jaring insang beratnya mencapai $59.466 \mathrm{~g}$ atau $11,73 \%$ dari berat total. Rinciannya adalah kembung $(7,36 \%)$, alu-alu $(1,25 \%)$ semar $(3,87 \%)$, galang sadap $(4,86 \% ;)$, kwee $(2,39 \%)$, tentengkek $(0,44 \%)$, dan bawal hitam $(0,17 \%)$. Jenis organisme paling banyak adalah kembung tergolong ikan pelagis kecil yang daerah penyebarannya meliputi daerah Indopasifik (Syah 2004). Jumlahnya tidak terlalu banyak dibandingkan dengan tongkol dan tenggiri, karena musim puncak penangkapannya terjadi pada bulan April (Prahadina et al. 2015). Penyebab lainnya adalah jaring insang yang digunakan dalam penelitian memiliki ukuran mata yang besar. Tujuannya untuk menangkap tongkol dan tenggiri. Jenis organisme yang banyak kedua adalah ikan galang sadap. Penyebab galang sadap tertangkap karena migrasi vertikal ke arah permukaan untuk mencari makan (Maherung et al. 2018). Makanannya adalah ikan-ikan yang berukuran kecil (Venu dan Kurup 2006).

Hasil tangkapan selanjutnya adalah semar dengan berat sebesar $11.319 \mathrm{~g}$ dari berat total hasil tangkapan sampingan jaring insang. Semar termasuk ikan demersal atau hidup di dasar perairan. FAO (2001) dan Pangalila et al. (2014) mengatakan habitat semar berada di perairan pesisir yang relatif dalam hingga $200 \mathrm{~m}$. Makanannya berupa plankton dan ikan-ikan kecil (Ashari et al. 2014). Semar melakukan migrasi vertikal harian untuk mencari makan, sehingga memungkinkan tertangkap oleh jaring insang. Adapun musim puncak penangkapannya berada antara Maret-Mei (Kompri 2013 dalam Ashari et al. 2014).

Kwee merupakan hasil tangkapan sampingan jaring insang dengan berat sebesar $6.988 \mathrm{~g}$ dari berat hasil tangkapan sampingan jaring insang. Randall et al. (1990) menyatakan ikan kwee aktif pada malam hari (nokturnal) dan bersifat karnivor. Makanannya berupa ikanikan kecil, chepalopod, dan krustacea. Habitatnya adalah perairan bersubstrat pasir, berbatu dan berkarang. Kwee berenang ke permukaan untuk mencari makan. Menurut Agustina (2016), musim puncak penangkapan kwee terjadi pada bulan Desember dan menurun drastis pada bulan Maret dan menyebabkan hasil tangkapan jaring insang tidak banyak.

HTS jaring insang dengan berat yang hampir sama adalah alu-alu, tentengkek, dan bawal hitam. Berat dan jumlahnya mencapai $(1,25 \%)$, $(0,44 \%)$, dan $(0,17 \%)$ dari berat total hasil tangkapan. Alu-alu termasuk jenis ikan pelagis yang hidup pada terumbu karang bagian dalam (FAO 2001). Penyebarannya sangat luas, yaitu mulai dari pantai sampai laut lepas (FAO 1974). Jenis makanannya berupa ikan, udang lobster dan cephalopods (Blaber 2000). Hosseini et al. (2009) menambahkan alu-alu umumnya hidup secara soliter pada daerah terumbu karang. Akibatnya, peluang alualu tertangkap oleh jaring insang semakin kecil. Tentengkek merupakan keluarga dari carangidae (Carpenter 2002). Habitatnya berada pada perairan berbatu dan terumbu karang. Biasanya hidup pada kedalaman 1-360 m. Makanannya berupa ikan-ikan pelagis, demersal, dan chepalopod (Harris et al. 2007). Makanan bawal hitam berupa plankton dan ikan-ikan kecil (Barata dan Prisantoso 2008). Habitat ikan bawal hitam berada di dasar perairan, terkadang berada di permukaan perairan, sehingga dapat tertangkap oleh jaring insang (Rachma et al. 2015).

\section{Hasil tangkapan JDL}

Penggunaan lampu LED pada pengoperasian jaring insang (JDL) menghasilkan 3 jenis HTU dan 7 jenis HTS. Berat HTU-nya mencapai $153.514 \mathrm{~g}$ atau $80,90 \%$ dari berat total hasil tangkapan. Jenis ikan yang mendominasi adalah tongkol seberat $90.237 \mathrm{~g}(47,55 \%)$. Jenis HTU lainnya berupa tenggiri $61.552 \mathrm{~g}(32,44 \%)$ 
dan talang $1.725 \mathrm{~g}(0,91 \%)$. Adapun HTS yang diperoleh JDL selama peneltian terdiri atas kembung $15.014 \mathrm{~g}(8,24 \%)$ dan alualu $1.900 \mathrm{~g}(0,84 \%)$, galang sadap $9.000 \mathrm{~g}$ $(4,74 \%)$, kwee $5.488 \mathrm{~g}(2,89 \%)$, semar 3.069 g $(1,62 \%)$, tentengkek $1.280(0,67 \%)$, dan hasil tangkapan terendah adalah bawal hitam $500 \mathrm{~g}(0,26 \%)$. Komposisi berat jenisnya dapat dilihat pada Gambar 6.

\section{Hasil tangkapan JTL}

Pengoperasian JTL mendapatkan 8 jenis yang terbagi atas 3 jenis HTU dan 5 jenis HTS. Hasil tangkapan jaring insang didominasi oleh HTU $79.360 \mathrm{~g}$, atau mencapai $77,37 \%$ dari berat total hasil tangkapan JTL. Adapun berat HTS hanya $23.215 \mathrm{~g}(22,63 \%)$. Tongkol menjadi jenis ikan yang mendominasi berat HTU, yaitu $42.150 \mathrm{~g}$ (41,09\%). Adapun jenis HTU lainnya, yaitu tenggiri $36.560 \mathrm{~g}(35,64 \%)$ dan talang $650 \mathrm{~g}(0,63 \%)$. Sementara bobot jenis ikan hasil tangkapan sampingannya dapat dirinci menjadi kembung $6.510 \mathrm{~g}(6,35 \%)$, alu-alu $1.755 \mathrm{~g}(1,71 \%)$, semar $8.250 \mathrm{~g}$ $(8,04 \%)$, galang sadap $5.200 \mathrm{~g}(5,07 \%)$, dan kwee $1.500 \mathrm{~g}(1,46 \%)$ dan Komposisi berat hasil tangkapan jaring insan tanpa lampu dapat di lihat pada Gambar 7 .

\section{Perbandingan hasil tangkapan JDL dan JTL}

Jaring insang dengan lampu (JDL) menangkap ikan seberat $189.765 \mathrm{~g}$ atau $64,91 \%$ dari berat total hasil tangkapan. Komposisinya terdiri atas 3 jenis organisme target dan 7 jenis organisme non target. Adapun jaring insang tanpa lampu (JTL) menghasilkan berat tangkapan $102.575 \mathrm{~g}$ $(35,09 \%)$ yang terdiri atas 3 jenis ikan target dan 5 jenis ikan non target. Rincian jenis dan berat masing-masing hasil tangkapan dijelaskan pada Gambar 8.

Berdasarkan Gambar 8 beberapa jenis hasil tangkapan JDL dan JTL adalah sama, yaitu tongkol, tenggiri, talangtalang, alu-alu, kembung, sadap, semar, dan kwee. Sementara jenis tentengkek dan bawal hitam hanya tertangkap oleh JDL. Harris et al. (2007) menyebutkan bahwa tentengkek merupakan jenis ikan karang yang memburu mangsanya berupa ikan pelagis, demersal, dan chepalopod. Adapun bawal hitam, merupakan jenis ikan dasar yang memiliki pola renang vertikal harian untuk mencari makan (Rachma et al. (2015).
Lampu akan menarik perhatian ikan untuk mendekatinya (Sudirman et al. 2003).

Berat HTU JDL mencapai 153.154 $\mathrm{g}$ atau lebih banyak dibandingkan dengan HTU JTL (79.360 g), begitu juga dengan HTS-nya. Masing-masing adalah $36.251 \mathrm{~g}$ dan 23.215 g. Penyebabnya, menurut Reppie et al. (2016), cahaya lampu akan menarik perhatian ikan-ikan kecil. Selanjutnya, kehadiran ikan-ikan kecil akan diikuti oleh kedatangan ikan HTU dan HTS yang berukuran lebih besar untuk memangsanya. Bubun et al. (2015) membuktikan bahwa ikan predator memangsa $95-100 \%$ nekton dan $0,4 \%$ zooplankton dan moluska. Hasil penelitian Syahdan et al. (2007) memperjelas bahwa keberadaan ikan planktivore, seperti teri atau ikan kecil lainnya sangat penting dalam jaringan makanan (food chain) di lautan karena merupakan penghubung antara plankton dengan ikan-ikan lain. Terbentuknya rantai makanan di sekitar lampu merupakan pengaruh dari cahaya (Simbolon 2010). Penggunaan alat bantu lampu Akan berpengaruh terhadap hasil tangkapan jaring insang. Hasil penelitian ini juga sejalan dengan Prasetyo (2017) bahwa penggunaan alat bantu lampu LED hijau pada jaring insang mampu mendapatkan hasil tangkapan utama yang lebih banyak. Pengujian secara statistik membuktikan bahwa hasil tangkapan JDL lebih berat dibandingkan dengan JTL. Artinya adalah penggunaan lampu pada jaring insang akan meningkatkan berat hasil tangkapan secara signifikan. Nilai signifikan yang diperoleh berdasarkan analisis non parametrik Mann-Whitney adalah 0,015, atau lebih kecil dibandingkan dengan nilai $F_{\text {Tabel }}(0,05)$ atau HO ditolak. Kesimpulannya adalah penggunaan lampu pada jaring insang mampu meningkatkan berat hasil tangkapan jaring insang.

\section{Sebaran hasil tangkapan pada JDL}

Ikan hasil tangkapan JDL pada saat penelitian menyebar pada semua lembar jaring (Gambar 9). Jumlah terbanyak berada pada posisi lembar jaring pertama atau lembar jaring yang dekat dengan lampu, yaitu lembar 1, 6, 7, dan 12. Beratnya mencapai $108.308 \mathrm{~g}$ atau $57,34 \%$ dari berat total ikan yang tertangkap. Adapun posisi lembar jaring kedua $(2,5,8$, dan 11$)$ menghasilkan $51.115 \mathrm{~g}(26,53 \%)$ dan lembar ketiga $(3,4,9$, dan 10) mendapatkan 30.342 g $(16,13 \%)$ (Gambar 10). 


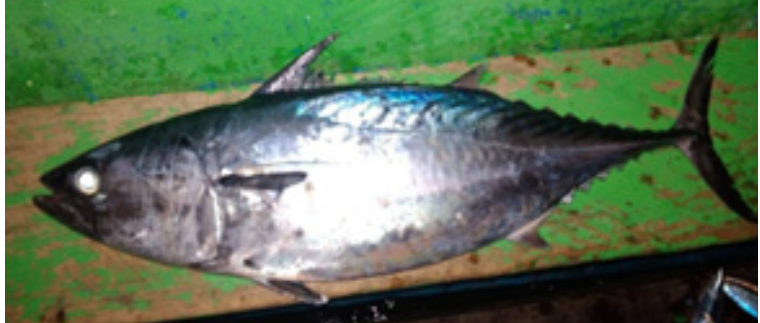

(a)

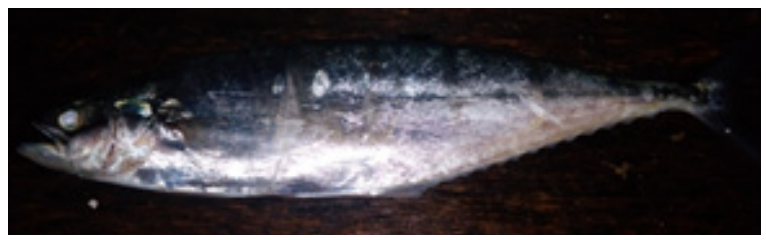

(c)

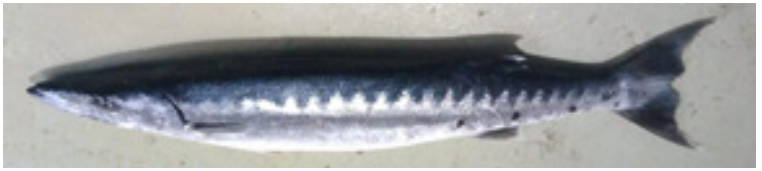

(e)

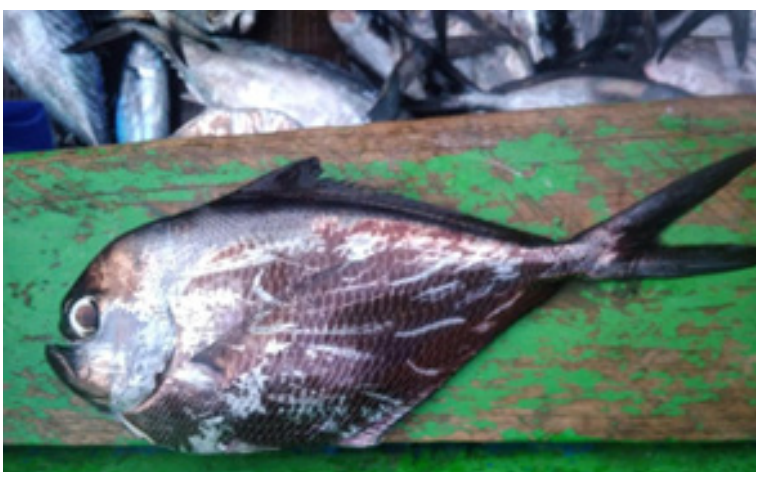

(g)

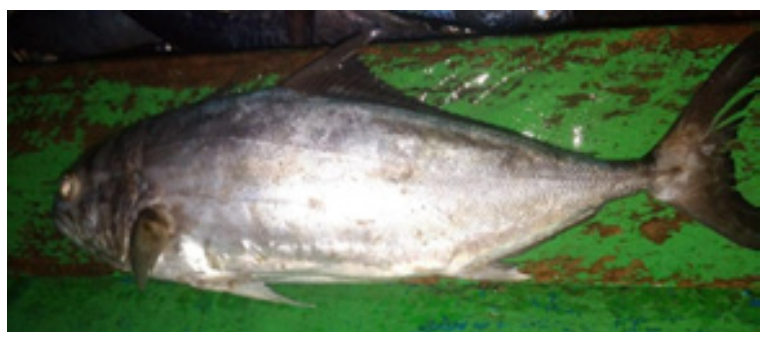

(i)

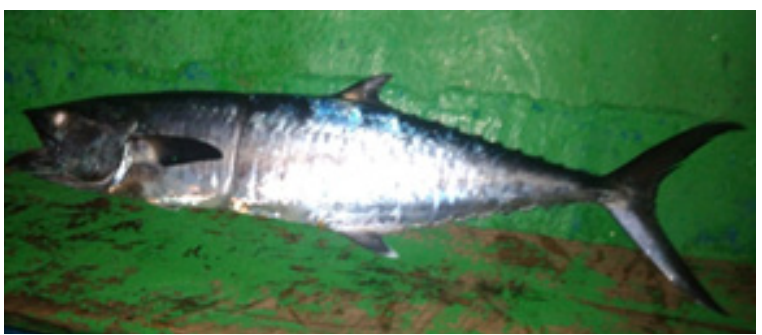

(b)

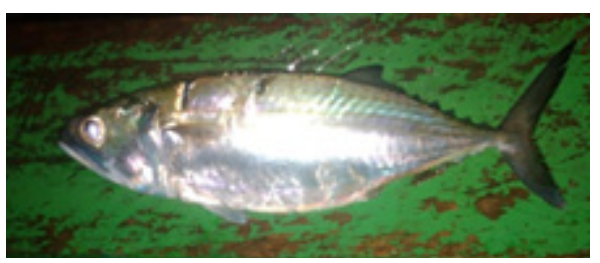

(d)

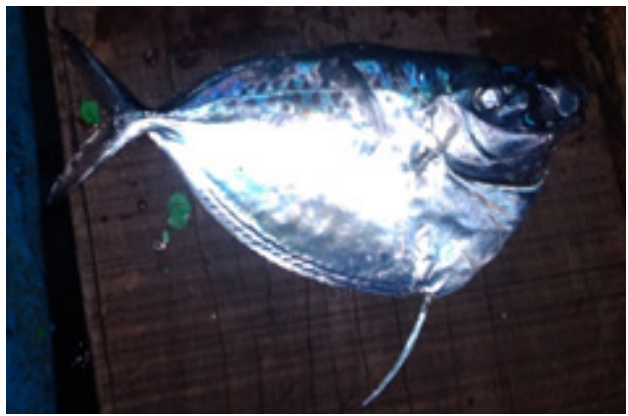

(f)

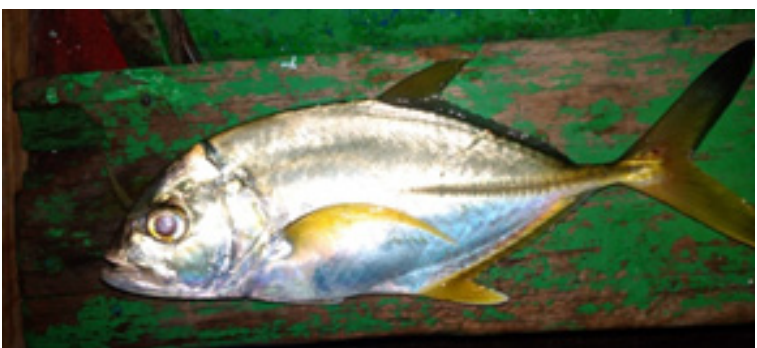

(h)

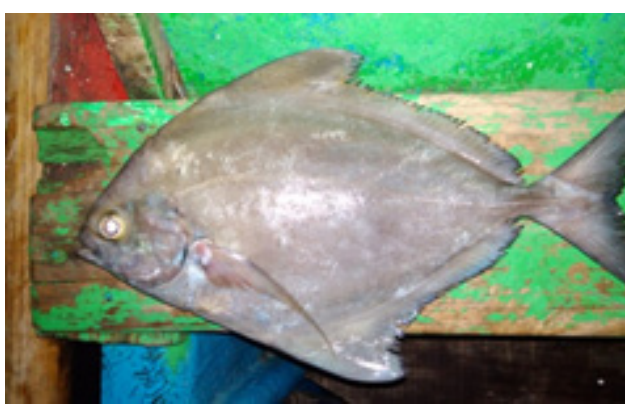

(j)

Gambar 4. Hasil tangkapan jaring insang: (a) Ikan tongkol (Euthynnus affinis), (b) Ikan tenggiri (Scomberomorus commerson), (c) Ikan talang-talang (Scomberoides tala), (d) Ikan kembung (Rastrelliger kanagurta), (e) Ikan alu-alu (Sphyraena barracuda), (f) Ikan semar (Mene maculata), (g) Ikan galang sadap (Brama orcini), (h) Ikan kwee (Caranx ignobilis), (i) Ikan Tentengkek (Seriolina nigrofasciata), (j) Ikan bawal (Parastromateus niger) 


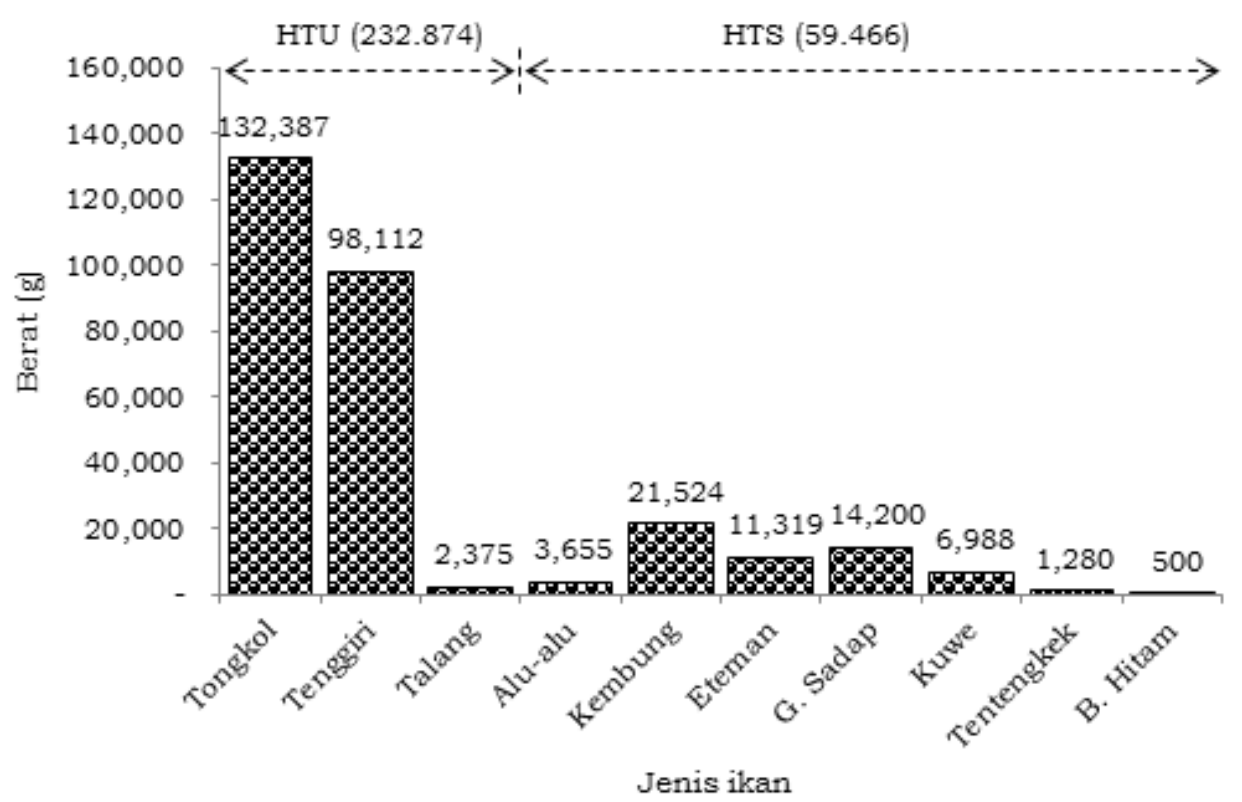

Gambar 5. Komposisi berat hasil tangkapan jaring insang

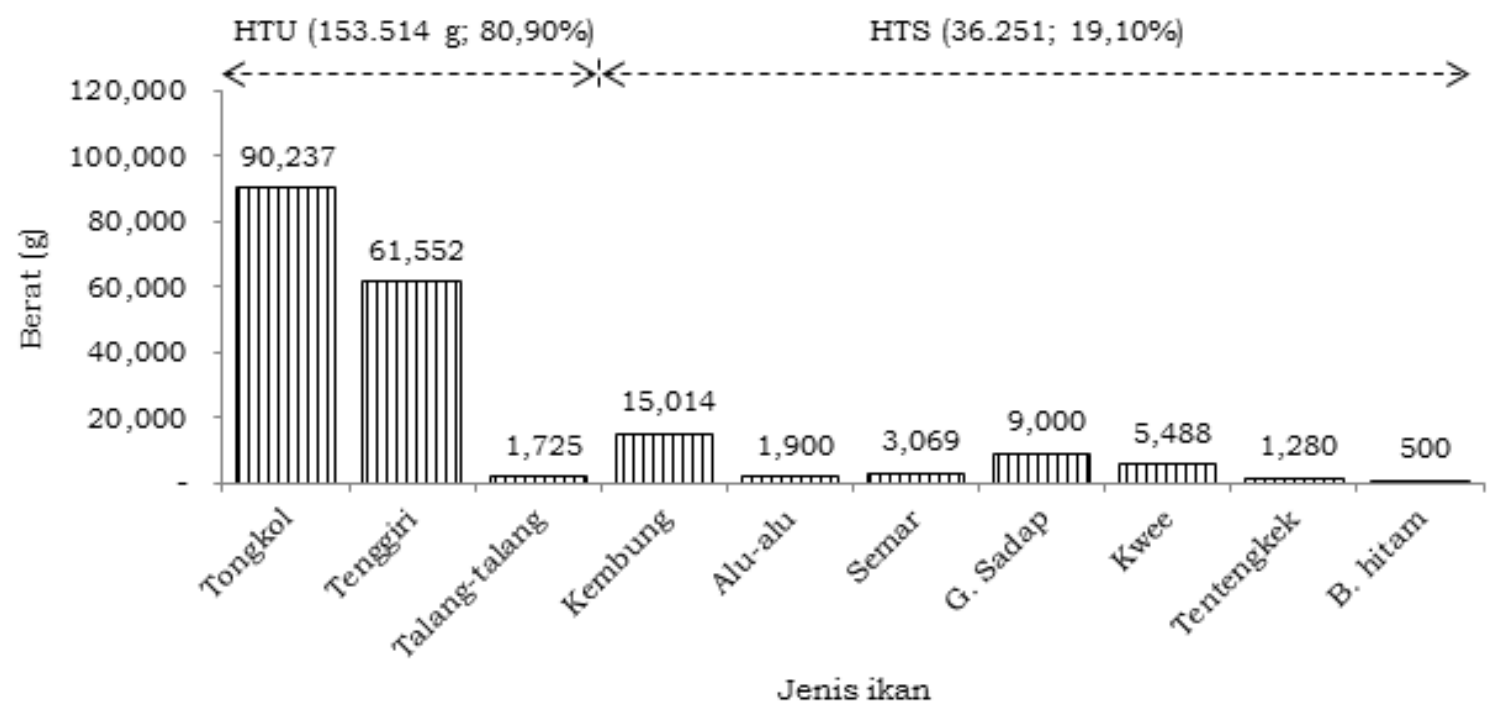

Gambar 6. Komposisi berat hasil tangkapan JDL

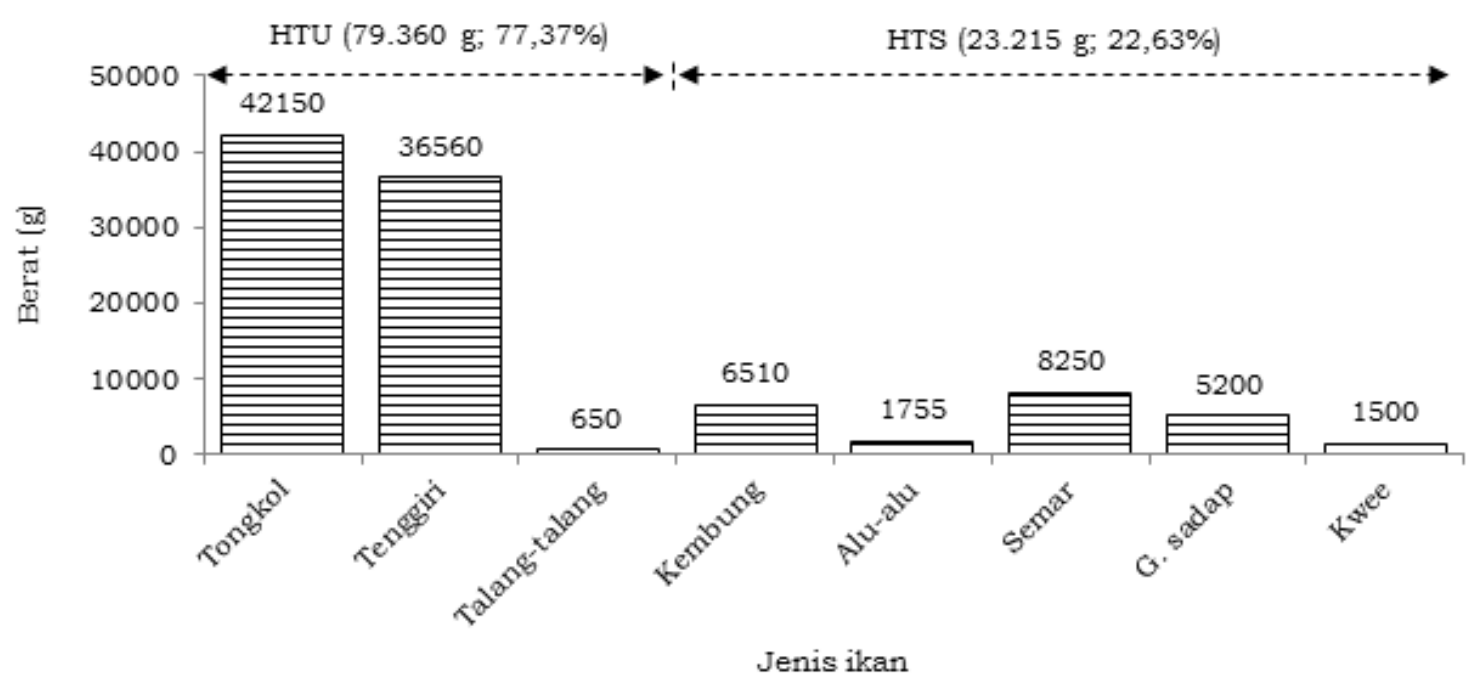

Gambar 7. Komposisi berat hasil tangkapan JTL 


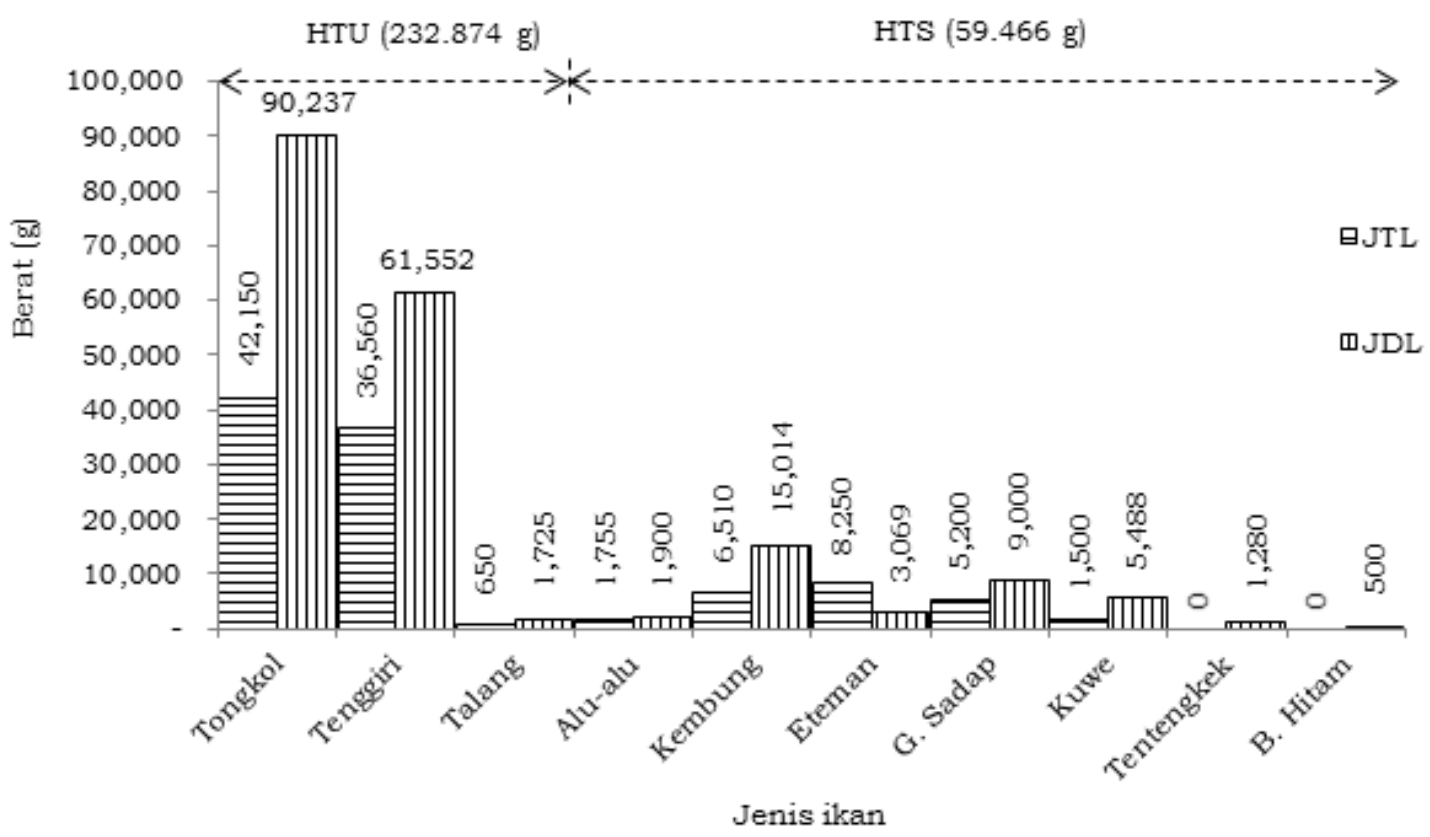

Gambar 8. Komposisi dan berat hasil tangkapan jaring insang

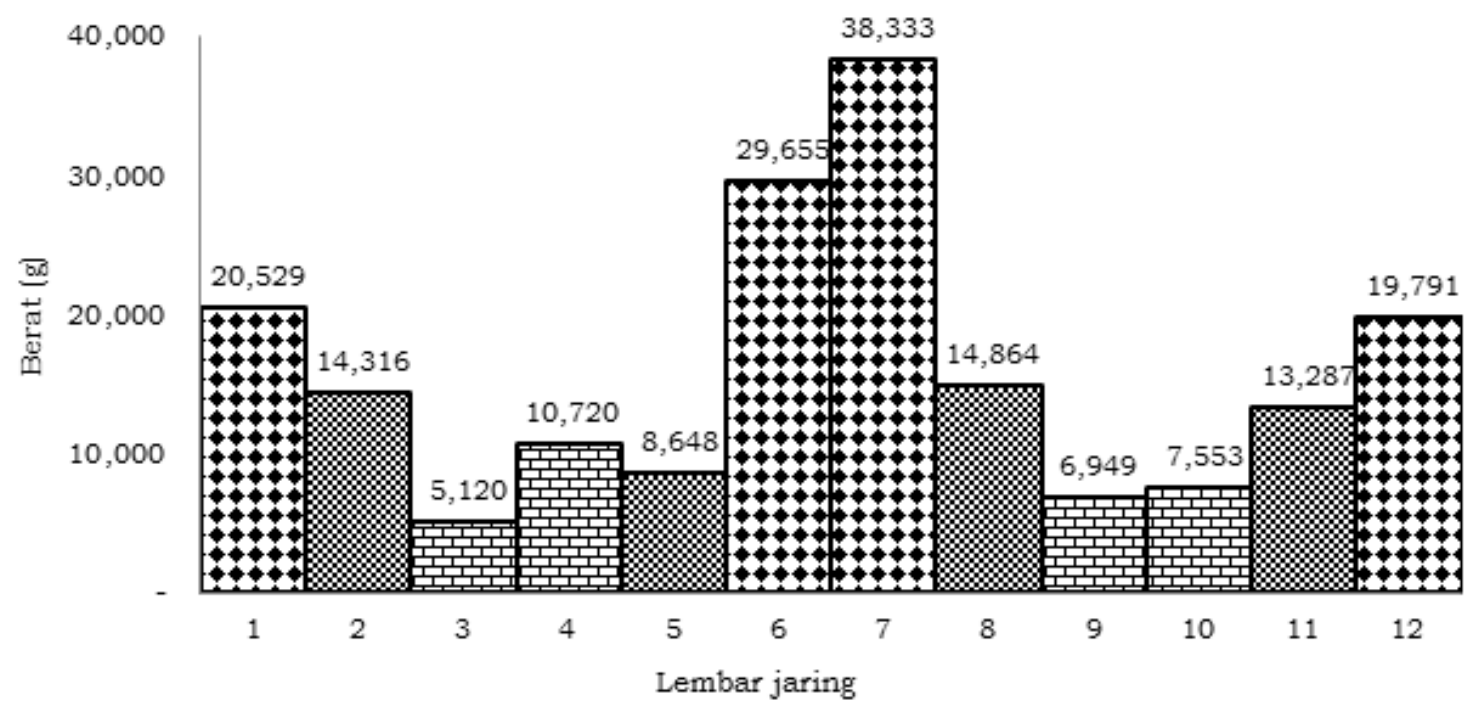

Gambar 9. Berat hasil tangkapan pada setiap lembar jaring

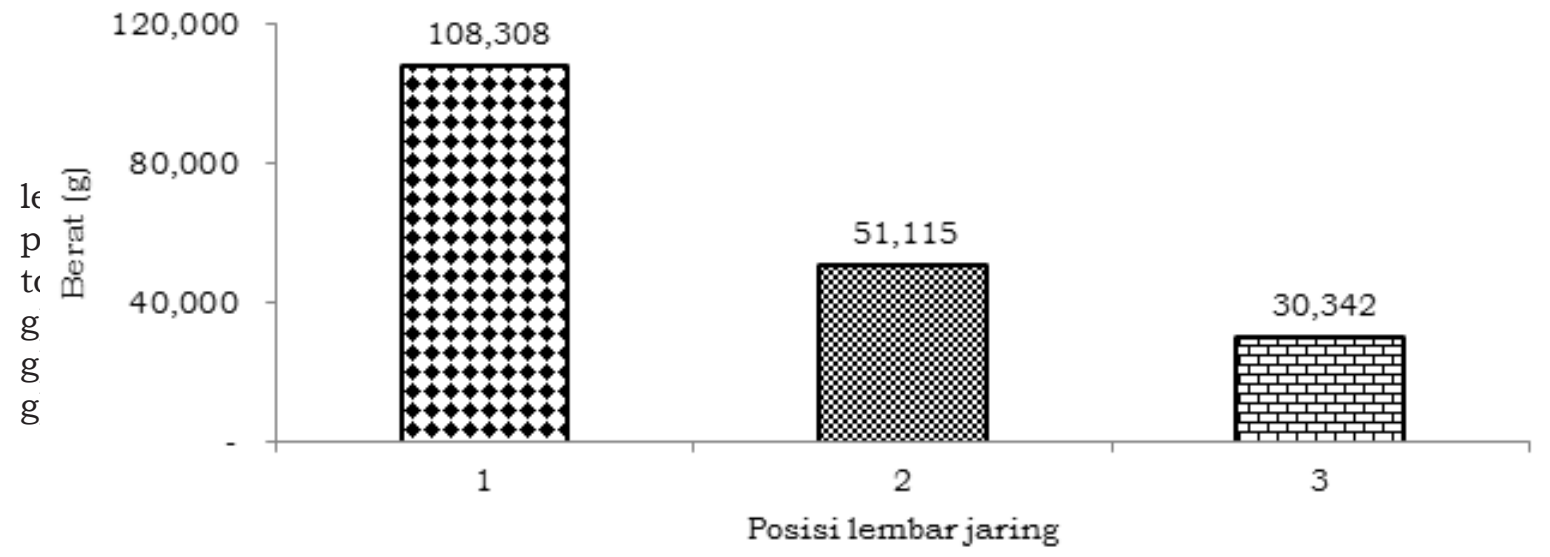

Gambar 10. Hasil tangkapan berdasarkan posisi lembar jaring 
Berat dan jenis ikan hasil tangkapan lebih banyak berada pada lembar jaring pertama (Gambar 10). Komposisinya, tongkol seberat $48.858 \mathrm{~g}$, tenggiri (31.298 g), kembung (12.446 g), talang-talang (1.725 g), galang sadap (5.100 g), semar (2.793 g), kwee (4.188 g), dan alu-alu (1.900 g). Selanjutnya, posisi lembar jaring kedua mendapatkan 6 jenis ikan dengan rincian tongkol seberat $27.077 \mathrm{~g}$, tenggiri (17.412 g), kembung (1.170 g), galang sadap (3.900 g), semar (276 g), dan tentengkek (1.280 g). Adapun lembar tiga, komposisi dan berat hasil tangkapannya paling sedikit. Masingmasing adalah tongkol seberat $14.302 \mathrm{~g}$, tenggiri (12.842 g), kembung (1.398 g), kwee (1.300 g), dan bawal hitam (500 g).

Cahaya pada JDL menarik perhatian ikan untuk mendekati sumber cahaya. Penyebabnya adalah cahaya menjadi indikasi berlimpahnya makanan (Gunarso 1985). Cahaya juga sangat membantu ikan untuk melihat mangsanya (Cahyadi dan You 2016). Pergerakan ikan menuju sumber cahaya akan terhadang dan selanjutnya terperangkap oleh lembar jaring yang lebih dekat dengan lampu. Ketertarikan ikan terhadap cahaya menjadi penyebab kenapa jumlah jenis ikan yang tertangkap pada jaring lembar 1, 6, 7, dan 12 lebih banyak dibandingkan dengan lembar lainnya.

Spesies yang tertangkap pada posisi lembar pertama, kedua dan ketiga relatif hampir sama, begitupun beratnya. Jumlah tangkapan yang lebih banyak pada lembar 1, 6, 7, dan 12 menyebabkan beratnya juga menjadi lebih tinggi dibandingkan dengan lembar lainnya. Hasil pengujian statistik membuktikan bahwa ada perbedaan hasil tangkapan yang nyata berdasarkan posisi jaring terhadap lampu. Uji non parametrik Kruskal Wallis menunjukkan bahwa jarak lampu terhadap jaring mempengaruhi hasil tangkapan jaring insang dengan nilai asymp. sig 0,002 $\leq 0,05$.

\section{KESIMPULAN DAN SARAN}

\section{Kesimpulan}

1. Ikan hasil tangkapan JDL terdiri atas 10 jenis, atau 2 jenis lebih banyak dibandingkan dengan JTL. Delapan jenis ikan yang sama adalah tongkol, tenggiri, talang-talang, alu-alu, kembung, semar, galang sadap, dan kwee. Adapun 2 jenis ikan yang hanya tertangkap oleh JDL adalah tentengkek dan bawal hitam,

2. Penggunaan alat bantu lampu pada jaring insang terbukti meningkatkan hasil tangkapan dengan berat hasil tangkapan JDL sebesar 189.765 g, dan

3. Lembar jaring yang menghasilkan berat tangkapan tertinggi berada pada posisi pertama, yaitu lembar 1, 6, 7, dan 12 dengan hasil tangkapan sebesar $108.308 \mathrm{~g}$.

\section{Saran}

1. Penggunaan lampu celup LED COB pada jaring insang perlu diuji coba pada perairan yang berbeda,

2. Penggunaan lampu LED COB perlu diuji coba pada jaring insang dengan diletakkan pada seluruh lembar jaring.

\section{DAFTAR PUSTAKA}

Adnan. 2010. Analisis Suhu Permukaan Laut dan Klorofil-A Data Inderaja Hubungannya dengan Hasil Tangkapan Ikan Tongkol (Euthynnus affinis) di Perairan Kalimantan Timur. Jurnal Amanisal PSP FPIK Unpati Ambon. 1(1): 1-12.

Agustina S, Irnawati R, Susanto A. 2016. Musim Penangkapan Ikan Pelagis Besar di Pelabuhan Perikanan Pantai Lempasing Provinsi Lampung. Jurnal Perikanan dan Kelautan. 6(1): 74-82.

Arif AM, Susanto A, Irnawati R. 2015. Konsumsi Bahan Bakar Lampu Tabung dan Lampu LED pada Generator Set Skala Laboratorium. Jurnal Perikanan dan Kelautan. 5(1): 25-32.

Ashari F, Redjeki S, Kunarso. 2014. Keterkaitan Jumlah Tangkapan Ikan Pelagis Kecil dengan Distribusi Klorofil-A dan Suhu Permukaan Laut Menggunakan Citra Satelit Modis di Laut Jawa dan Selat Makassar. Journal of Marine Research. 3(3): 366373.

Barata A, Prisantoso BI. 2008. Beberapa Jenis Ikan Bawal (Angel fish, Bramidae) yang Tertangkap dengan Rawai Tuna (Tuna Long Line) di Samudera Hindia dan Aspek Penangkapannya. BAWAL. 2(5): 231-235.

Baskoro MS, Yusfiandayani R. 2015. Metode Penangkapan Ikan. Bogor (ID): Institut Pertanian Bogor.

Blaber SJM, 2000. Tropical Estuarine 
Fishes: Ecology, Exploitation, and Conservation. 1st Edn., Blackwell Sci., Oxford.

Blaber SJM, Brewer DT, Salini JP. 1989. Species Composition and Biomasses of Fishes in Different Habitats of a Tropical Northern Australian Estuary: Their Occurrence in the Adjoining Sea and Estuarine Dependence. Estuarine, Coastal, and Shelf Science. 29: 509-531.

Bubun RL, Simbolon D, Nurani TW, Wisudo SH. 2015. Terbentuknya Daerah Penangkapan Ikan dengan Light Fishing. Jurnal Airaha. 4(1): 27-36.

Cahyadi A, You WX 2016. Rekayasa LED Ikan Melalui Pengaturan Lumensi Cahaya Berbasis Perangkat Lunak Versi Betha. Jurnal Kelautan Nasional. 11(2): 119-125.

Carpenter KE. 2002. The Living Marine Resources of the Western Central Atlantic, Volume 3: Bony Fishes, Part 2 (Opistognathidae to Molidae), Sea Turtles and Marine Mammals. FAO (Food and Agriculture Organization of the United Nations) Species Identification Guide For Fishery Purposes and American Society of Ichthyologists and Herpetologists Special Publication 5. FAO; Rome.

Collette BB, Aadland CR. 1996. Revision of the Frigate Tunas (Scombridae, Auxis), with Descriptions of Two New Subspecies from the Eastern Pacific. Fish. Bull. 94: 423-441.

Direktorat Kredit, BPR dan UMKM. 2008. Pola Pembiayaan Usaha Kecil (PPUK) - Penangkapan Ikan Pelagis dengan Alat Tangkap Gillnet. Jakarta (ID): Bank Indonesia.

FAO. 1974. FAO Identification Sheets for Fishery Purpose "Fishing Area East Indonesia Ocean, Western Central Pacific". UNDP/FAO Published; Rome.

FAO. 2001. FAO Species Identification Guide for Fishery Purposes "The Living Marine Resources of The Western Central Pacific". FAO; Rome (ITA).

Fitri ADP, Asriyanto. 2011. Respon Penglihatan Ikan Baronang dan Kakap Merah terhadap Perbedaan Warna Jaring (Skala Laboratorium) [prosiding]. Yogyakarta (ID): Universitas Gajah Mada.

Griffiths S, Fry G, Velde TVD. 2005. Age, Growth, and Reproductive Dynamics of the Talang Queenfish
(Scomberoides commersonnianus) in Northern Australia. Final Report to the National Oceans Office. CSIRO Cleveland. pp. 39.

Gunarso W. 1985. Tingkah Laku Ikan dalam Hubungannya dengan Alat, Metode, dan Taktik Penangkapan. Bogor (ID): Fakultas Perikanan, Institut Pertanian Bogor.

Harris PJ, Wyanski DM, White DB, Mikell PP. 2007. Age, Growth, and Reproduction of Greater Amberjack of the Southeast US Atlantic Coast. Transaction of the American Fisheries Society. 136: 1534-1545.

Hosseini SA, Jamili S, Valinassab T, Vosoghi G, Fatemi SMR. 2009. Feeding and Spawning of Sphyraena jello in the North-West of Persian Gulf. Journal of Fisheries and Aquatic Science. 4(1): 57-62.

Imron M, Iskandar MD. 1998. Studi Posisi Ikan Tangkapan pada Perikanan Encircling Gillnet Menggunakan Rumpon LampudiPerairan Palabuhan Ratu. Bogor (ID): Lembaga Penelitian dan Pengabdian Masyarakat, Institut Pertanian Bogor.

Imron M, Wiyono ES, Iskandar MD. 1997. Eksplorasi Ikan Pelagis dengan Jaring Insang Lingkar (Encircling gilnet) dengan Alat Bantu Drift Rumpon Lampu di Perairan Pelabuhan Ratu. Bogor (ID): Lembaga Penelitian dan Pengabdian Masyarakat, Institut Pertanian Bogor.

Iskandar D, Suzuki Y, Shiode D, Hu F, Tokai T. 2007. Pengaruh Pemasangan Umpan terhadap Daya Tangkap Gillnet. Bogor (ID): Institut Pertanian Bogor.

Maherung S, Bataragoa NE, Salaki MS. 2018. Ukuran dan Kebiasaan Makan Ikan Kwee (Caranx spp) di Daerah Intertidal Sekitar Laboratorium Basah FPIK Unsrat Likupang. Jurnal Ilmiah Platax. 6(1): 6-11.

Notanubun J, Patty W. 2010. Perbedaan Penggunaan Intensitas Cahaya Lampu terhadap Hasil Tangkapan Bagan Apung di Perairan Selat Rosenberg Kabupaten Maluku Tenggara Kepulauan Kei. Jurnal Perikanan dan Kelautan. 6(3): 134140.

Pangalila FPT, Budiman J, Telleng ATR, Reppie E. 2014. Kajian Perikanan Tangkap Mene maculata di Teluk Buyat. Jurnal IPTEKS PSP. 1(2): 103- 
111.

Prahadina VD, Boer M, Fahrudin A. 2015. Sumberdaya Ikan Kembung (Rastrelliger kanagurta Cuvier 1817) di Perairan Selat Sunda yang Didaratkan di PPP Labuan, Banten. Marine Fisheries. 6(2): 169-175.

Prasetyo GD. 2017. Penggunaan Lampu LED (Light Emitting Diode) Hijau terhadap Pengurangan Bycatch Penyu pada Perikanan Gillnet di Perairan Paloh [Tesis]. Bogor (ID): Institut Pertanian Bogor.

Puspito G. 2009. Perubahan Sifat-Sifat Fisik Mata Jaring Insang Hanyut Setelah Digunakan 5, 10, 15, dan 20 Tahun. Jurnal Penelitian Sains. 12.3: 1-6.

Rachma H, Ghofar A, Saputra SW. 2015. Studi Beberapa Aspek Biologi Ikan Bawal Hitam (Parastromateus niger) yang Tertangkap Payang di Kabupaten Kendal. Diponegoro Journal of Maquares. 4(4): 1-9.

Randall JE, Allen GR, Steene RC. 1990. Fishes of the Great Barrier Reef and Coral Sea. University of Hawai Press. North America. 507 pp.

Reppie E, Patty W, Sopie M, Taine K. 2016. Pengaruh Pemikat Cahaya Berkedip pada Bubu terhadap Hasil Tangkapan Ikan Karang. Marine Fisheries. 7(1): 25-32.

Salas S, Gaertner D. 2004. The Behavioural Dynamics of Fishers: Management Implications. Fish and Fisheries. (5): 153-167.

Setiawan F, Sri RS, Ageng S. 2015. Analisis Pengaruh Medium Perambatan terhadap Intensitas Cahaya Lacuba (Lampu Celup Bawah Air). Jurnal Rekayasa dan Teknologi Elektro. 9(1): 21-29.

Simbolon D, Sondita MFA, Amiruddin. 2010. Komposisi Isi Pencernaan Ikan Teri (Stolephorus spp.) di Perairan Barru, Selat Makassar. Ilmu Kelautan. 15(1): 7-16.

Situmorang DM, Agustriani F, Fauziyah. 2018. Analisis Penangkapan Ikan Tenggiri (Scomberomorus sp.) yang Didaratkan di PPN Sungailiat, Bangka. Jurnal Maspari. 10(1): 8188.

Sokimi W, Beverly S. 2010. Small Scale Fishing Techniques Using Lght: A Manual for Fishermen. Noumea, New Caledonia: Secretariat of the Pacific Community. $61 \mathrm{p}$.

Sudirman, Baskoro MS, Purbayanto A,
Monintja DR, Arimoto T. 2003. Profil Pencahayaan dan Distribusi Ikan pada Areal Penangkapan Bagan Rambo di Selat Makassar. Prosiding Seminar Nasional Perikanan Indonesia. 3: 28-42.

Sudirman, Nessa N. 2011. Perikanan Bagan dan Aspek Pengelolaannya. Malang (ID): Universitas Muhammadiyah Malang.

Suhardi D. 2014. Prototipe Controller Lampu Penerangan LED (Light Emitting Diode) Independent Bertenaga Surya. Jurnal Gamma. 10(1): 116-122.

Surahman A, Kuswoyo A. 2016. Aspek Penangkapan Jaring Kembung di Tanjung Balai Asahan, Selat Malaka. Buletin Teknik Litkayasa. 14(2): 1-4.

Susanto A, Fitri ADP, Putra Y, Susanto H, Alawiyah T. 2017. Respons dan Adaptasi Tingkah Laku Ikan Teri terhadap Lampu Light Emitting Diode (LED). Marine Fisheries. 8(1): 39-49.

Syah US. 2004. Kajian Perkembangan Produksi Histamin Selama Penanganan Bahan Pengolahan dan Penyimpanan pada Ikan Kembung (Rastrelliger spp) [Tesis]. Bogor (ID): Institut Pertanian Bogor.

Syahdan M, Sondita MFA, Atmadipoera A, Simbolon D. 2007. Hubungan Suhu Permukaan Laut dan Klorofil-A terhadap Hasil Tangkapan Cakalang (Katsuwonus pelamis) di Perairan Bagian Timur Sulawesi Tenggara. Buletin PSP. XVI(2): 246-260.

Syam AR, Satria H. 2009. Adaptasi Fisiologis Retina Mata dan Tingkah Laku Ikan terhadap Cahaya. Bawal. 2(5): 215224.

Venu S, Kurup BM. 2006. Distribution and Biology of Deep Sea Fishes Neoepinnula orientalis Gilchrist and Von Bonde 1924 and Psenes squamiceps Lloyd, 1909 from West Coast of Indian EEZ. Journal of the Marine Biological Association of India. 48(1): 24-28.

Walpole RE, Myers RH, Myers SL, Ye K. 2007. Probability dan Statistic for Engginers and Scientists: Eight Edition. New Jersey (USA): Pearson prentice Hall

Wiyono ES. 2012. Pengaruh Lama Melaut dan Jumlah Hauling terhadap Hasil Tangkapan Ikan pada Perikanan Gillnet Skala Kecil di Pekalongan Jawa Tengah. Jurnal Teknologi Perikanan dan Kelautan. 3(2): 57-64. 